University of Nebraska - Lincoln

DigitalCommons@University of Nebraska - Lincoln

8-1-2006

\title{
Assembly of high-anisotropy L10 FePt nanocomposite films
}

David J. Sellmyer

University of Nebraska-Lincoln, dsellmyer@unl.edu

Yinfan Xu

University of Nebraska - Lincoln, yxu2@unl.edu

M. L. Yan

University of Nebraska-Lincoln, myan@unlserve.unl.edu

Yucheng Sui

University of Nebraska-Lincoln, ysui2@unl.edu

Jian Zhou

University of Nebraska - Lincoln

See next page for additional authors

Follow this and additional works at: https://digitalcommons.unl.edu/physicssellmyer

Part of the Physics Commons

Sellmyer, David J.; Xu, Yinfan; Yan, M. L.; Sui, Yucheng; Zhou, Jian; and Skomski, Ralph, "Assembly of highanisotropy L10 FePt nanocomposite films" (2006). David Sellmyer Publications. 94.

https://digitalcommons.unl.edu/physicssellmyer/94

This Article is brought to you for free and open access by the Research Papers in Physics and Astronomy at DigitalCommons@University of Nebraska - Lincoln. It has been accepted for inclusion in David Sellmyer Publications by an authorized administrator of DigitalCommons@University of Nebraska - Lincoln. 


\section{Authors}

David J. Sellmyer, Yinfan Xu, M. L. Yan, Yucheng Sui, Jian Zhou, and Ralph Skomski 


\title{
Assembly of high-anisotropy $\mathrm{L1}_{0}$ FePt nanocomposite films
}

\author{
D. J. Sellmyer, Yingfan Xu, Minglang Yan, Yucheng Sui, Jian Zhou and R. Skomski \\ Department of Physics and Astronomy, Center for Materials Research and Analysis, University of Nebraska-Lincoln
}

Available online 17 February 2006; in print August 2006.

\begin{abstract}
In this paper we report results on the synthesis and magnetic properties of $\mathrm{L}_{0}$ FePt nanocomposite films. Three fabrication methods have been developed to produce high-anisptropy FePt films: non-epitaxial growth of $\left(\begin{array}{lll}0 & 0\end{array}\right)$-oriented FePt:X (X=Ag, C) composite films that might be used for perpendicular media; monodispersed FePt $\left(\mathrm{CF}_{x}\right)$ core-shell nanocluster-assembled films grown with a gas-aggregation technique and having uniform cluster size and narrow size distribution; and template-mediated self-assembled FePt clusters prepared with chemical synthesis by a hydrogen reduction technique, which has a high potential for controlling both cluster size and orientation. The magnetic properties are controllable through variations in the nanocluster properties and nanostructure. Analytical and numerical simulations have been done for these films, providing better understanding of the magnetization reversal mechanisms. The films show promise for development as magnetic recording media at extremely high areal densities.
\end{abstract}

Keywords: FePt, Nanoclusters, $\mathrm{L1}_{0}$ ordering, Magnetic anisotropy, Nanocomposite

\section{Introduction}

Recently $\mathrm{L}_{0}$ ordered FePt, CoPt nanoparticles have been studied intensively because they have high potential for technological applications, such as extremely high-density magnetic recording (EHDR) media and nanocomposite permanent magnets $[1,2,3]$. For example, the noise reduction for EHDR at areal densities approaching $1 \mathrm{~Tb} / \mathrm{in}^{2}$ requires the medium to have decoupled or weakly interacting magnetic grains that are in the range $4-8 \mathrm{~nm}$ with a narrow size distribution $[4,5,6]$. Present CoCrPtX type media almost approach the superparamagnetic limit as grain size deceases below $10 \mathrm{~nm}$; the thermal stability factor, $K_{\mathrm{u}} V^{*}$ / $k_{\mathrm{B}} T$, where $K_{\mathrm{u}}$ is the anisotropy constant and $V^{*}$ an activation volume, becomes less than about 50 which is required for 10-year storage. FePt and CoPt have large values of $K_{\mathrm{u}}\left(\sim 5-7 \times 10^{7} \mathrm{erg} / \mathrm{cm}^{3}\right)$ [7], and thus have the potential to serve as building blocks for thermally stable $\mathrm{Tb} / \mathrm{in}^{2}$ media.

In this paper, we report on recent efforts to fabricate high-anisotropy $\mathrm{L}_{0}$ FePt nanocomposite films by three methods: monodispersed core-shell $\mathrm{FePt}\left(\mathrm{CF}_{x}\right)$ nanocluster-assembled films grown with a gas-aggregation source

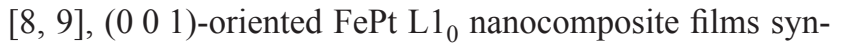
thesized by non-epitaxial growth of multilayers [10, 11], chemical synthesis of $\mathrm{FePt} \mathrm{L1} 1_{0}$ particles in nanoporous alumina and creation of highly anisotropic particle films under external magnetic field [12], and analytical and numerical simulational results on these systems [13].

\section{2. $\operatorname{FePt}\left(\mathrm{CF}_{x}\right)$ core-shell nanoclusters with $\mathrm{C}$ matrix}

A core-shell FePt nanocluster system, in which the magnetic core is coated with a layer of a non-magnetic shell, is of great interest for study and tailoring magnetic properties such as magnetization, anisotropy and interparticle interactions [14]. The core-shell structure is expected to enable an increase of the packing density of the cluster-assembled films and the shell may serve as isolation between the clusters, resulting in the decrease of exchange coupling. 

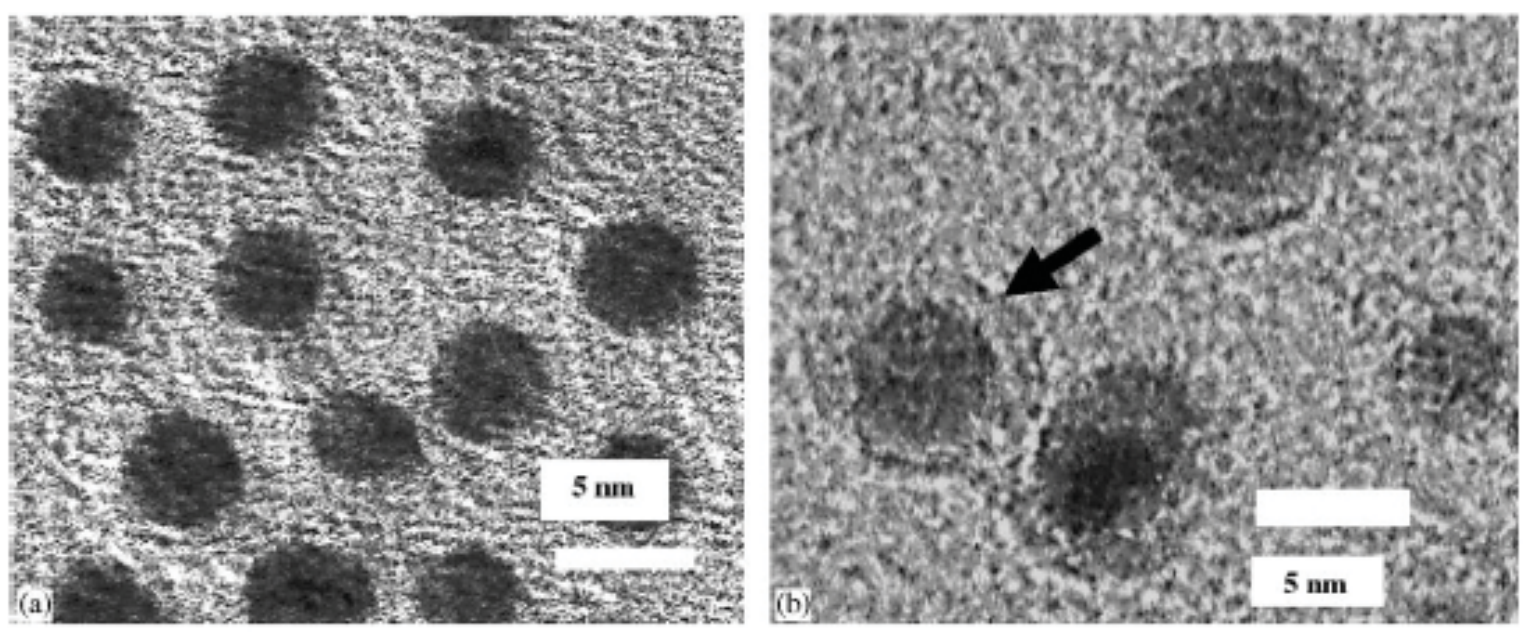

Fig. 1. TEM images of FePt $\left(\mathrm{CF}_{x}\right)$ nanoclusters: (a) as-deposited; (b) annealed at $600{ }^{\circ} \mathrm{C}$ for $10 \mathrm{~min}$. The arrow indicates the shell structure.

We have prepared monodispersed FePt clusters with fluorocarbon $\left(\mathrm{CF}_{x}\right)$ shell synthesized by a gas-aggregation technique $[8,9]$. To form core-shell clusters, $\mathrm{CF}_{x}$ gas was applied to the gas-aggregation chamber with various flow rates. The clusters were either directly deposited onto a Si substrate or embedded in a $\mathrm{C}$ matrix. Fig. 1 (a) shows the TEM image of uniform $\mathrm{FePt}\left(\mathrm{CF}_{x}\right)$ clusters with average diameter of about $4.5 \mathrm{~nm}$ in the as-deposited state. The shell structure can be observed in a film annealed at $600{ }^{\circ} \mathrm{C}$ for $10 \mathrm{~min}$. (Fig. 1(b)). High magnetic anisotropy of $\mathrm{L1}_{0} \mathrm{FePt}\left(\mathrm{CF}_{x}\right)$ cluster-assembled films was realized via post-deposition annealing at different temperatures $\left(500{ }^{\circ} \mathrm{C}-700{ }^{\circ} \mathrm{C}\right)$ for $10 \mathrm{~min}$. Fig. 2 shows the effect of annealing temperature on the coercivity of films deposited on a Si substrate. The coercivity was enhanced with addition of $\mathrm{CF}_{x}$ gas, which implies a decrease of the ordering temperature by about $50^{\circ} \mathrm{C}$.

Embedding the clusters in a carbon matrix was found to isolate clusters from sintering effectively during annealing $[15,16]$. Fig. 3 shows a TEM image of the $\operatorname{FePt}\left(\mathrm{CF}_{x}\right)$ clusters embedded in a $\mathrm{C}$ matrix; a structure free of agglomeration was observed after annealing at $650{ }^{\circ} \mathrm{C}$ for $10 \mathrm{~min}$. Interparticle interactions were studied by measuring the $\Delta M$ curves for annealed films [17]. $\Delta M$ was found to be positive for clusters directly deposited on $\mathrm{Si}$ and negative for clusters embedded in $\mathrm{C}$ matrix, indicating the change from dominant exchange interactions to dipolar interactions by embedding clusters into the $\mathrm{C}$ matrix. Our results indicate that the magnetic properties of the core-shell $\mathrm{FePt}\left(\mathrm{CF}_{x}\right)$ nanoclusters can be easily tuned for various nanomagnetic applications.

\section{Non-epitaxial growth of ( $\left(\begin{array}{lll}0 & 1\end{array}\right)$-textured $\mathrm{L1}_{0}$ FePt:X nanocomposite films}

Under normal growth conditions, $\mathrm{L1}_{0}$-phase FePt and FePtbased films often possess $\left(\begin{array}{lll}1 & 1 & 1\end{array}\right)$ preferred or random orientations. In order to control the crystal orientation, epi-

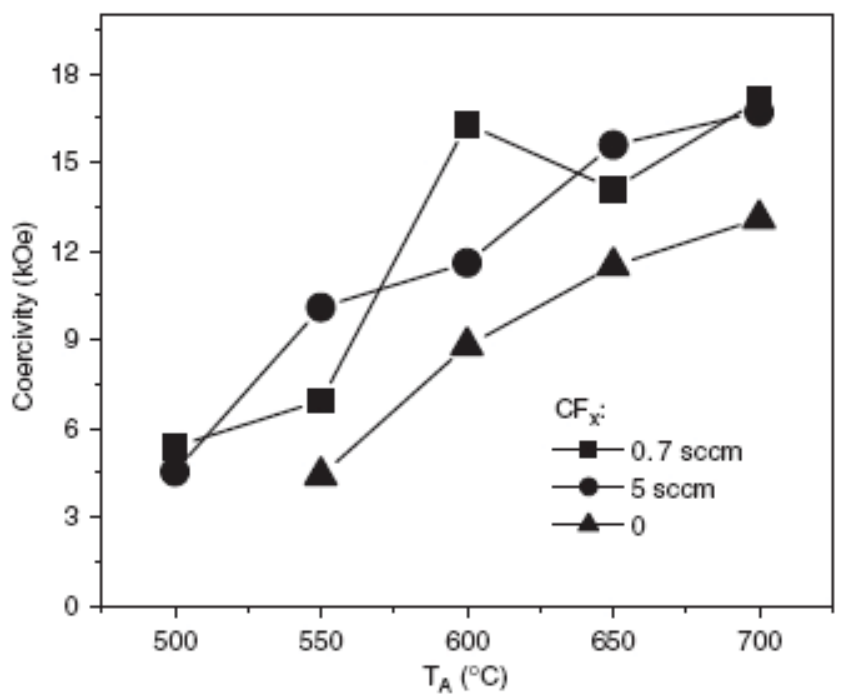

Fig. 2. Annealing temperature dependence of coercivity for $\operatorname{FePt}\left(\mathrm{CF}_{x}\right)$ and FePt clusters.

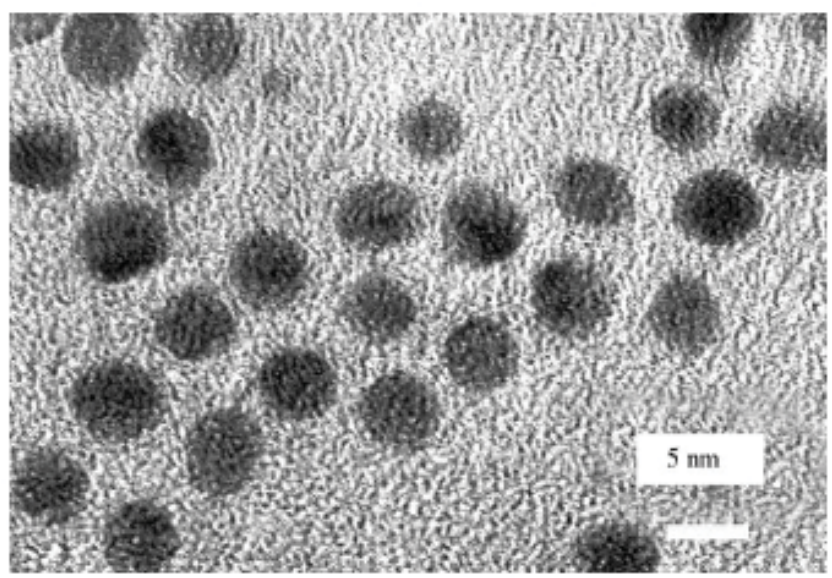

Fig. 3. TEM image of $\mathrm{FePt}\left(\mathrm{CF}_{x}\right)$ clusters embedded in $\mathrm{C}$ matrix and annealed at $650{ }^{\circ} \mathrm{C}$ for $10 \mathrm{~min}$. 
taxial growth of the FePt film is needed. The most common methods to obtain the $c$-axis normal to the film plane $\left[\begin{array}{lll}0 & 0 & 1\end{array}\right)$ texture $]$ are to use seed or buffer layers, such as $\mathrm{MgO}$. Recently, non-epitaxially grown, highly $\left(\begin{array}{lll}0 & 0 & 1\end{array}\right)$-textured $\mathrm{L} 1_{0} \mathrm{FePt}[9,10]$ and FePt based films [18] have been obtained by using multilayer deposition plus post annealing. It is found that orientations of FePt grains are affected by many preparation parameters, such as initial as-deposited film structure, composition, annealing time and so on $[19,20]$.

Fig. 4 shows X-ray diffraction patterns of $\mathrm{L}_{0} \mathrm{FePt}$ : $\mathrm{Ag}$ nanocomposite films. The Ag content varied from 0 to 20 vol\%. As shown in Fig. 4, all films clearly show the ( $\left.\begin{array}{lll}0 & 0 & 1\end{array}\right)$ superlattice peaks indicating that the Ag content (matrix) has relatively small effect on orientation. The coercivities and the hysteresis-loop slope parameter $(\alpha=\mathrm{d} M /$ $\mathrm{d} H\left(H_{c}\right)$ ) were determined from the hysteresis loops. With increasing $\mathrm{Ag}$ content the hysteresis-loop slope and the correlation length decrease, whereas the coercivity increases. The Ag increases the separation between the particles, thereby effectively exchange-decoupling the grains [19].

Hysteresis loops for $\mathrm{L} 1_{0}$ nanocomposite FePt:C film are shown in Fig. 5. The inset is the XRD pattern of the same FePt:C film, on which $\left(\begin{array}{ll}0 & 0\end{array}\right)$, (002) peaks appeared indicating that FePt grains are $\left(\begin{array}{lll}0 & 0 & 1\end{array}\right)$ oriented. The full-width at half-maximum (FWHM), obtained from the rocking curve of $\left(\begin{array}{lll}0 & 0 & 1\end{array}\right)$ peak, is $1.68^{\circ}$ confirming a high degree of ( $\left.\begin{array}{lll}0 & 0 & 1\end{array}\right)$ texturing. The loop shows perpendicular anisotropy with square shape in the perpendicular direction due to the preferential FePt $\mathrm{L1}_{0}\left(\begin{array}{lll}0 & 0 & 1\end{array}\right)$ texture. The perpendicular loop shows large coercivity $\left(\mathrm{H}_{\mathrm{c}}=6.2 \mathrm{kOe}\right)$ and high remanence ratio $(S=0.9)$ [20].

The nanostructure of non-epitaxially grown $\mathrm{L}_{0} \mathrm{FePt}$ : $\mathrm{C}$ thin film was characterized by TEM. As shown in Fig.

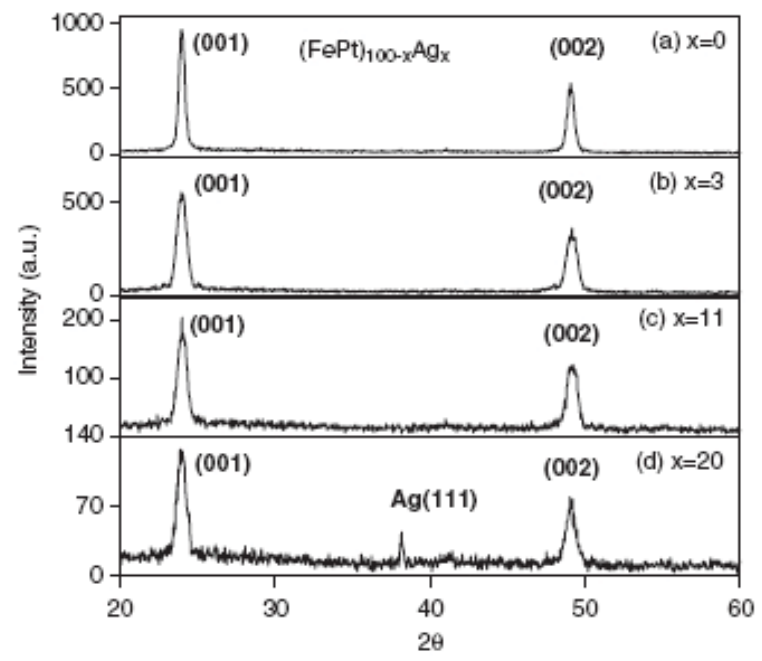

Fig. 4. XRD patterns of FePt:Ag films with different Ag content. Films deposited directly on Si wafer and annealed at $600{ }^{\circ} \mathrm{C}$ for $10 \mathrm{~min}$. Film thickness is $10 \mathrm{~nm}$.

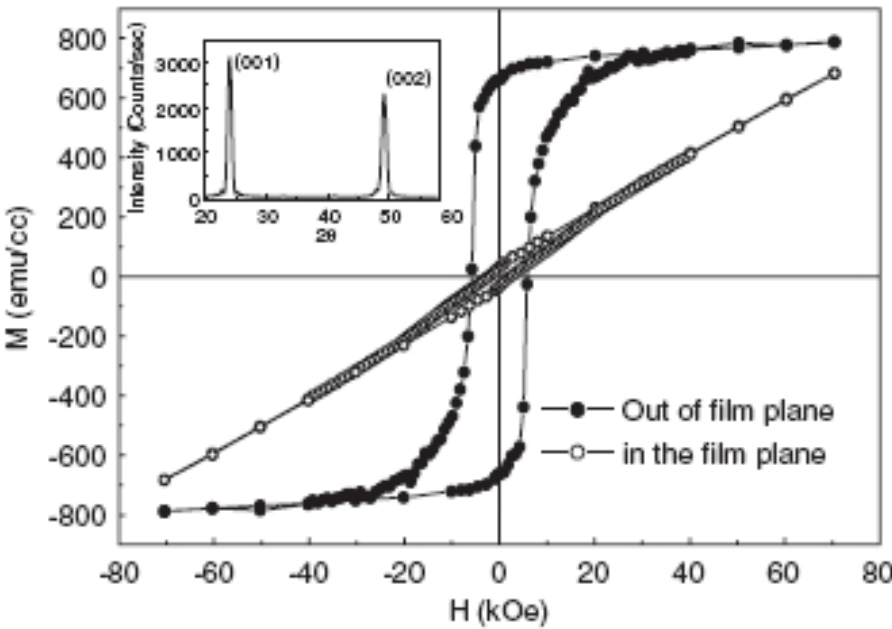

Fig. 5. Hysteresis loop of FePt:C film. Film deposited directly on Si wafer and annealed at $550{ }^{\circ} \mathrm{C}$ for $5 \mathrm{~min}$. Film thickness is $16 \mathrm{~nm}$. Inset is the XRD pattern of this sample.
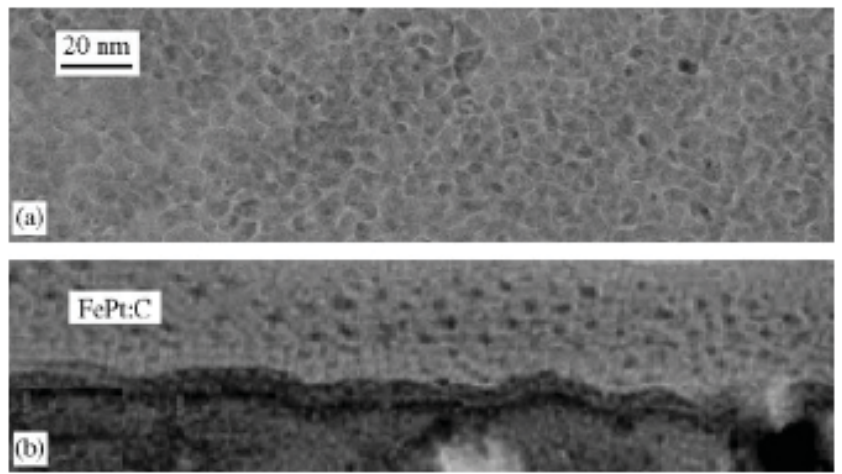

Fig. 6. TEM bright-field plane-view (a) and cross-section (b) images of FePt:C film.

6, the bright-field plane-view (a) and cross-section (b) images reveals that FePt grains with grain size of about $5 \mathrm{~nm}$ are embedded in the carbon matrix and appear to be well isolated.

\section{Template-mediated self-assembly of patterned nano- magnets}

Self-organized arrays of equiatomic FePt nanoparticles with ordered $\mathrm{L} 1_{0}$ structures are attractive as ultrahigh density magnetic recording media. The solution-phase-based synthesis offers a convenient way to produce monodispersed FePt clusters with the size being controlled down to only a few nanometers [21], but the postannealing step is indispensable for the transformation from the disordered FCC to chemically ordered FCT structure.

It is well known that template-mediated synthesis represents an elegant and efficient approach for producing nanostructured materials $[22,23]$. Porous alumina templates have many advantages over others [24]; for example, they are resistant to the attack of most organic and in- 
organic compounds and stable at high temperature. Also, these templates can be easily removed in sodium hydroxide aqueous solution, and the pore size, separation and distribution can be tuned.

When the hydrogen reduction reactions of a proper mixture of Pt and Fe salts are conducted within the nanochannels of the porous alumina templates, chemically ordered FePt and CoPt clusters are produced [12], which is demonstrated to be an efficient approach for direct synthesis of $\mathrm{L}_{0}$ structured FePt clusters without postannealing.

The combination of the $\mathrm{L}_{0}$ structured FePt clusters made by hydrogen reduction with the porous alumina templates leads to a novel scheme for constructing ordered ar-

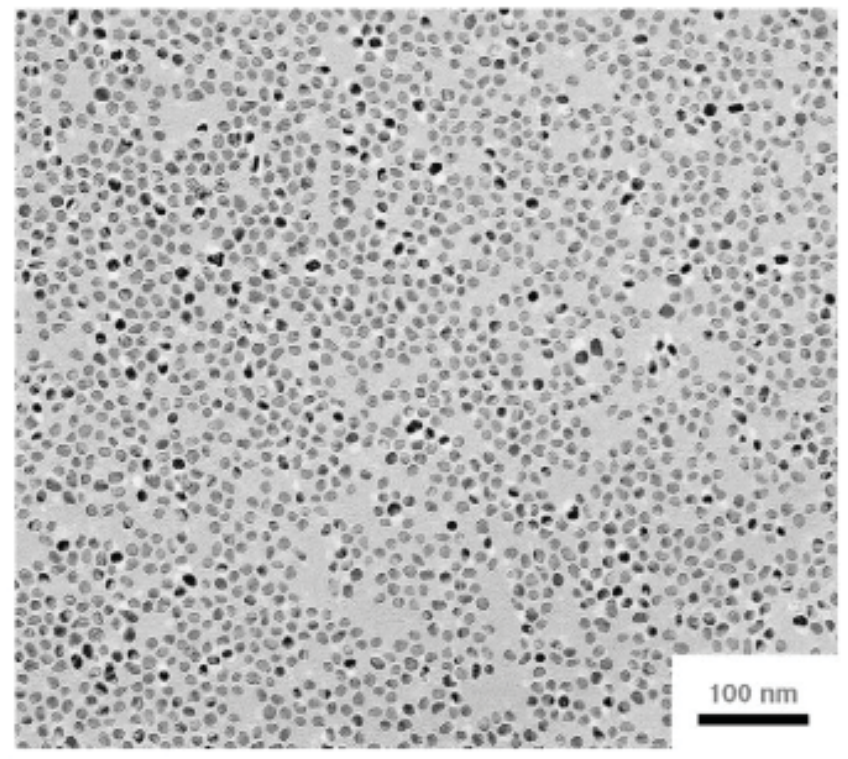

Fig. 7. TEM image of the FePt clusters assembly on a copper grid with $10 \mathrm{~nm}$ a carbon coating. rays of FePt clusters with anisotropic magnetic properties. It is called template-mediated assembly of $\mathrm{FePt} \mathrm{L}_{0}$ clusters under external magnetic field. The details of this new method are described briefly in the following.

When an alcohol solution of $\mathrm{Fe}\left(\mathrm{NO}_{3}\right)_{3} \cdot 9 \mathrm{H}_{2} \mathrm{O}$ and $\mathrm{H}_{2} \mathrm{PtCl}_{6} \cdot 6 \mathrm{H}_{2} \mathrm{O}$ (Fe:Pt=1:1) mixture is loaded into porous alumina discs and heated in flowing hydrogen at $650^{\circ} \mathrm{C}$ for $5 \mathrm{~min}, \mathrm{FePt}$ clusters were formed inside the pores. They are released from the alumina discs and capped with organic surfactants. After proper chemical processings, the FePt clusters with average diameter about $16 \mathrm{~nm}$ can be precipitated out and dispersed in hexane for further assembly. The alumina templates with ordered pore distribution are made by a twostep anodization of aluminum foils. The templates are fixed between two poles of an electromagnet with pores parallel to a magnetic field up to 1 Tesla. Assembly of FePt clusters onto alumina templates is accomplished by drop casting. Fig. 7 shows a TEM image of the FePt clusters assembly on a $\mathrm{Cu}$ grid coated with $10 \mathrm{~nm}$ carbon film. Fig. 8(a) shows an AFM topographic image and Fig. 8(b) shows an MFM image of the closed end of the pores after removing the aluminum film [12]. Hysteresis loops of the FePt dots arrays were measured by SQUID at room temperature. They have coercivities of 13.4 and $10.2 \mathrm{kOe}$ respectively when measured perpendicular and parallel to the plane of the dots arrays.

\section{Theoretical calculations}

To investigate magnetization reversal in nanostructures of $\mathrm{L1}_{0} \mathrm{FePt}$ nanograins and clusters, we have performed LLG micromagnetic simulations. The large uniaxial anisotropy $K_{1}$ of $\mathrm{FePt}$ is the basis for creating coercivity $H_{\mathrm{c}}$ in $\mathrm{L}_{0^{-}}$ based permanent magnets and magnetic recording media $[14,20]$. However, the corresponding Stoner-Wohlfarth prediction $H_{c}=2 K_{1} / \mu_{\mathrm{o}} M_{\mathrm{s}}$ significantly overestimates the co-

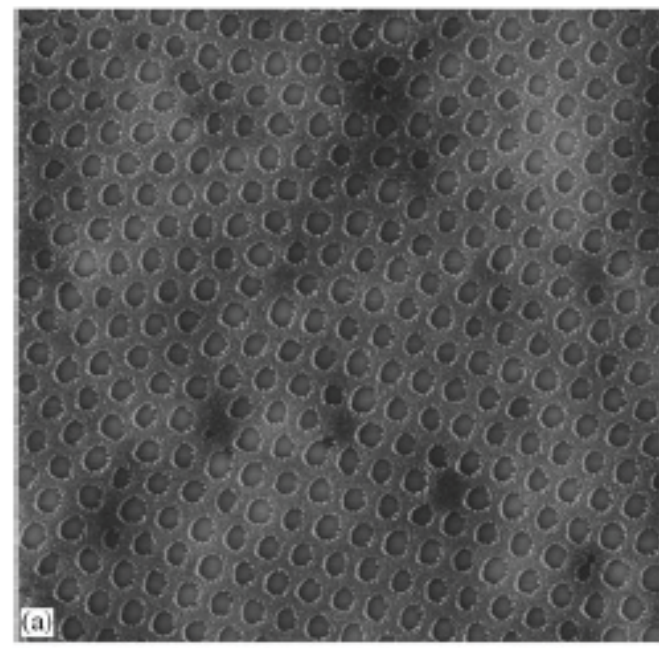

0

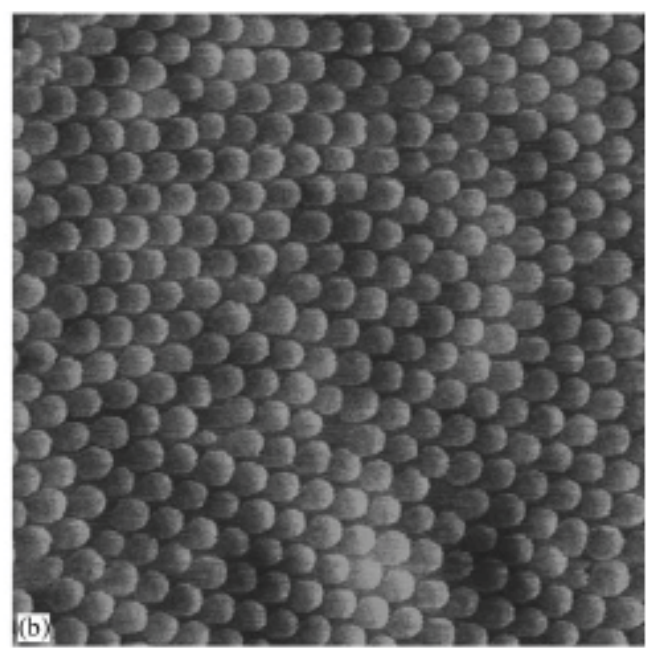

$2 \mu \mathrm{m}$

Fig. 8. AFM topography (a) and MFM image (b) on the bottom of the pores after removing aluminum matrix. 
ercivity, because it ignores the real structure of the magnets $[25,26]$. There are two main reasons for the reduced coercivity: intragranular imperfections and intergranular interactions, including domain-wall pinning effects.

\subsection{Core-shell nanoparticles}

To a large extent, the physics of inhomogeneous magnetic systems is contained in the core-shell model. This reflects magnetocrystalline surface and interface anisotropy $[26,27]$. Very recently [28], it has been shown that missing $3 \mathrm{~d}-4 \mathrm{~d} / 5 \mathrm{~d}$ bonds at surfaces and interfaces yield a disproportionally strong reduction of the anisotropy, in agreement with earlier results [29].

Here we consider magnetic particles characterized by reduced surface anisotropy. Nucleation-field analysis, i.e., considering perpendicular magnetization modes $m$ of the type $\mathrm{M}=\mathrm{M}_{\mathrm{s}}\left(\sqrt{1-\mathrm{m}^{2} \mathrm{e}_{z}}+\mathrm{m}\right)$, yields [26]

$$
\nabla^{2} m+\kappa(r)^{2} m=0
$$

where $\kappa^{2}(r)=\left(K_{1}(r)+\mu_{\mathrm{o}} M_{\mathrm{s}} H / 2\right) / A$. The magnetization modes $m(r)$ are obtained as eigenmodes of Eq. (1) subject to the free surface boundary condition $\mathrm{d} m / \mathrm{d} r=0$. In addition, $A \mathrm{~d} m / \mathrm{d} r$ and $m$ are continuous inside the material [30], but since $A$ is much less real-structure dependent than $K_{1}$, it is usually sufficient to assume that both $\mathrm{d} m / \mathrm{d} r$ and $m$ are continuous.

For spherical geometries, solutions of Eq. (1) are spherical Bessel functions. The nucleation behavior of stepwise continuous profiles $K_{1}(r)=K_{\mathrm{h}}$ for $r<R-\Delta R$ and $K_{1}(r)=K_{\mathrm{s}}$ for $R-\Delta R<r<R$ amounts to a superposition of functions of the type $\sin (x) / x, \cos (x) / x$, and $\sinh (x) / x$. Fig. 9 shows the explicit radial dependence of perpendicular component $|m|$. Fig. 10 shows the nucleation-field coercivity for a soft shell of thickness $0.5 \mathrm{~nm}$. The assumed core and shell anisotropies are 5 and $0.05 \mathrm{MJ} / \mathrm{m}^{3}$, respectively. The shallow small-

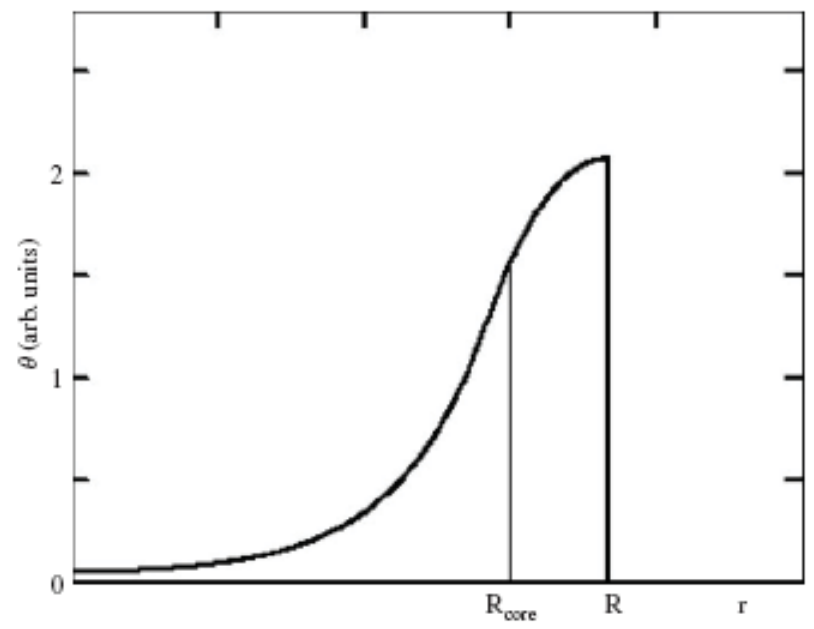

Fig. 9. Analytical results for size dependence of spheres' spin structure.

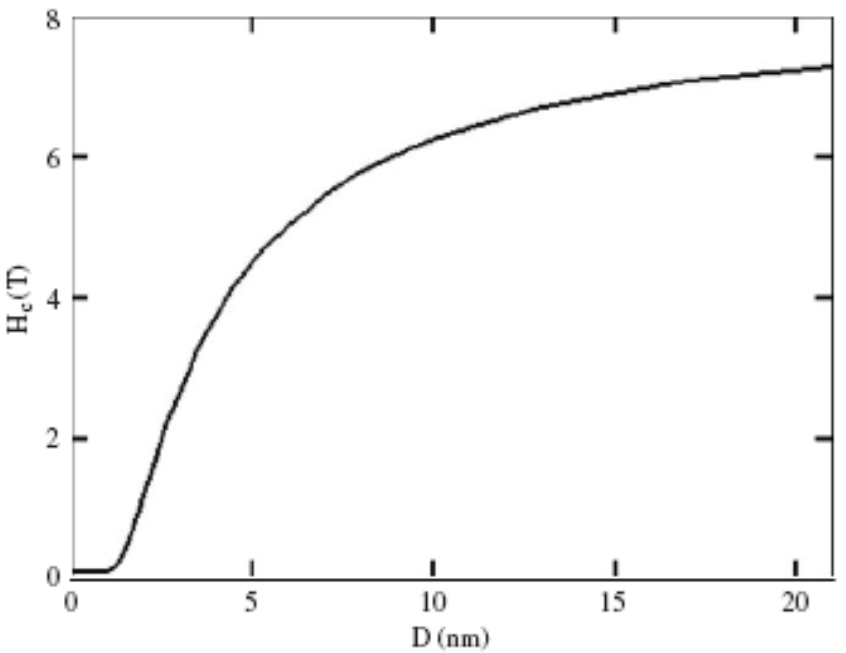

Fig. 10. Coercivity as a function of the particle diameter $D=2 R$ for typical $\mathrm{L} 1_{0}$ parameters.

particle minimum indicates the vanishing of the hard-magnetic phase when $\Delta R=R$. For $R=\infty, \mathrm{H}_{\mathrm{c}}$ remains smaller than $2 K_{1} / \mu_{\mathrm{o}} M_{\mathrm{s}}$ due to surface nucleation.

\subsection{Micromagnetic simulations}

The OOMMF code provided by NIST is used to perform micromagnetic simulation ( http://math.nist.gov/oommf ). The simulations are based on the Landau-Lifshitz-Gilbert equation. The parameters used in the simulations are: anisotropy constant $K_{1}=4-6 \mathrm{MJ} / \mathrm{m}^{3}$, exchange constant $\mathrm{A}=$ $10 \mathrm{pJ} / \mathrm{m}$, and saturation magnetization $\mathrm{M}_{\mathrm{s}}=0.8-1 \mathrm{MA} / \mathrm{m}$. For $\mathrm{L}_{0}$ FePt single particles, the observed coercivity in experiment, about $20 \mathrm{kOe}$, is much smaller than the bulk anisotropy field $H_{\mathrm{A}}=2 K_{1} / M_{\mathrm{s}}$, of $120 \mathrm{kOe}$. This is because at the nanometer scale, surface effects are important which distinguishes the surface and interface from the bulk property. Considering this, we consider a single sphere of $\mathrm{FePt}$ with a core-shell magnetic structure. A sphere with $6.7 \mathrm{~nm}$ diameter contains 417 cubic cells with unit length $0.75 \mathrm{~nm}$. This sphere has bulk properties of FePt with $\mathrm{K}_{1}=6 \mathrm{MJ} / \mathrm{m}^{3}$ and $\mathrm{M}_{\mathrm{s}}=1 \mathrm{MA} / \mathrm{m}$, with uniaxial anisotropy. The outer shell of the sphere, which has a thickness of $0.75 \mathrm{~nm}$, is assigned a reduced anisotropy due to interface imperfections.

Micromagnetic calculation shows a reduced anisotropy field of $80 \mathrm{kOe}$, and coercivity of $60 \mathrm{kOe}$, due to the reduced surface anisotropy [13]. This behavior qualitatively explains the observed discrepancy between $H_{\mathrm{c}}$ and $H_{\mathrm{A}}$ shown in Fig 5.Due to the lack of magnetic hardness, and the even more complicated nanostructure, including percolation of particles and imperfect alignment of the easy axes of the nanoparticles, observed coercivity is even smaller. However, the simple core-shell magnetic structure gives a qualitative explanation to the reduction of coercivity of FePt L1 $1_{0}$ nanoparticles. 


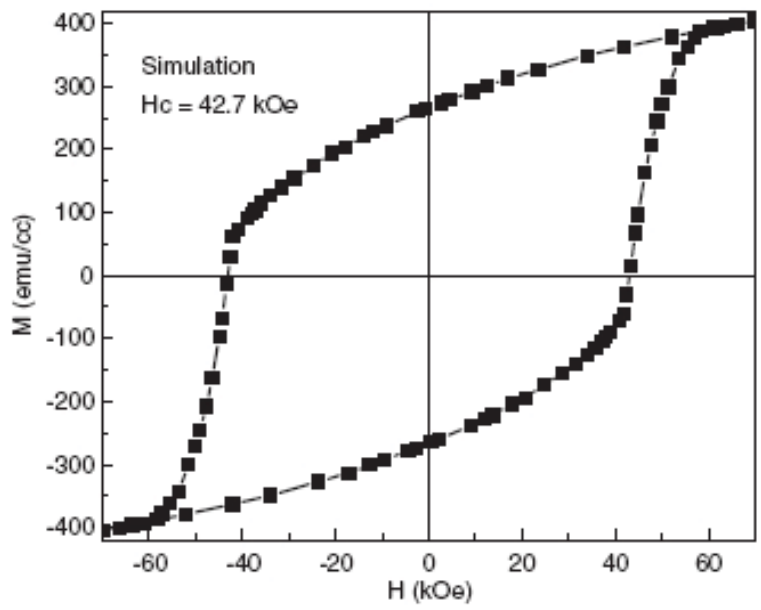

Fig. 11. Simulated hysteresis for assembly of isolated nanoclusters.

The system of diluted FePt:C nanoclusters is simulated to examine the coherent rotation (Stoner-Wohlfarth particles) behavior. For clusters with diameter size of $5 \mathrm{~nm}$ and well separated by the $\mathrm{C}$ matrix, there is no intergranular exchange interaction. In the OOMMF program, $27 \mathrm{L1}_{0} \mathrm{FePt}$ spheres are arranged in a cubic lattice, with center-to-center distance as $9 \mathrm{~nm}$, corresponding to a $5 \mathrm{vol} \% \mathrm{FePt}$ spheres in $\mathrm{C}$ matrix. The anisotropy axis of each sphere is randomly oriented. The simulated magnetic hysteresis loop shown in Fig. 11 represents hysteresis of randomly oriented Stoner-Wohlfarth particles without intergranular exchange interactions [25]. The loop matches the experimental result well $\left(H_{\mathrm{c}}(10 \mathrm{~K})=40.3 \mathrm{kOe}\right)[16]$, indicating the diluted FePt nanoclusters reverse as Stoner-Wohlfarth particles.

\subsection{Exchange dependence of coercivity}

In a nanocomposite system, the magnetically hard nanoparticles isolated by a magnetic matrix have different types of magnetization reversal depending on the matrix. The coercivity mechanism for such a system changes from the coherent-rotation regime for no exchange interactions to discrete pinning for large exchange interactions [31]. Both analytical and numerical simulations show a coercivity maximum during the transition between the two regimes. A system with $18 \mathrm{FePt}$ spheres with $7 \mathrm{~nm}$ diameter arranged in a two-layer rectangular lattice is simulated. The chosen anisotropies for the materials are $6 \mathrm{MJ} / \mathrm{m}^{3}$ for FePt and $2 \mathrm{MJ} / \mathrm{m}^{3}$ for matrix (for example, FeNiPt). To show the exchange dependence of coercivity, the exchange constant $A$ of the matrix is varied. Fig. 12shows that with an increasing exchange constant $A$, the coercivity of the system reaches a maximum and then decreases. This figure shows that the magnetization reversal transits from nucleation-type regime to discrete-pinning-type regime with increasing exchange $[13,31]$.

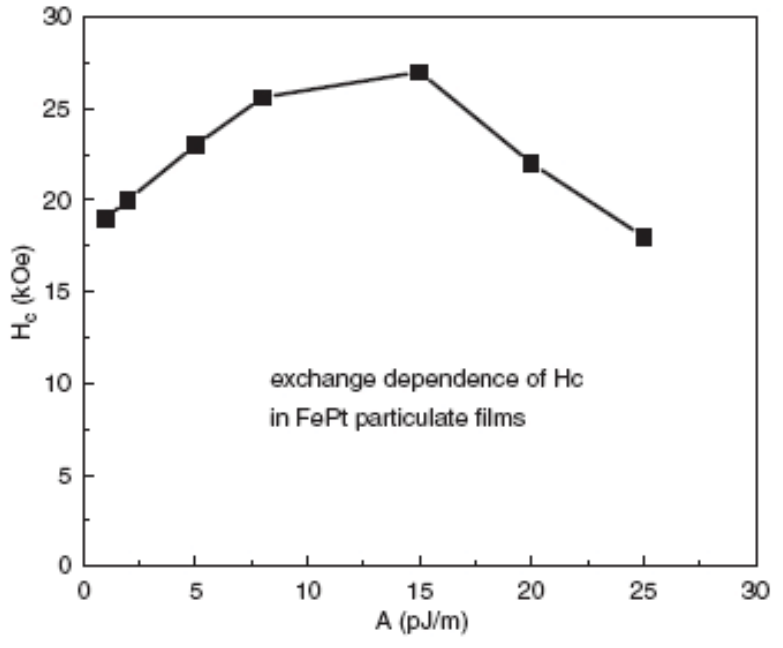

Fig. 12. Exchange dependence of coercivity of nanocomposites.

\section{Summarized Conclusions}

Monodispersed core-shell FePt $\left(\mathrm{CF}_{x}\right)$ uniform nanoclusters with very narrow size distribution were prepared by the gas-aggregation technique. High anisotropy and high coercivity depend on the system, with or without matrix, packing fraction, annealing temperature, etc. Exchange coupling of nanoparticles can be reduced by separation with a $\mathrm{C}$ matrix. Magnetic properties can be tuned for various nanomagnetic applications.

In the non-epitaxially grown films, development of excellent $\left(\begin{array}{lll}0 & 0 & 1\end{array}\right)$ texture of the clusters is quite interesting. Multilayering of the $\mathrm{Fe} / \mathrm{Pt}$ and individual layer thickness play an important role, but other metallurgical effects including strain, diffusion rates, etc., also may play important roles. The grain size distribution, degree of $\mathrm{L} 1_{0}$ ordering, intercluster exchange interactions, and magnetization reversal mechanism are issues that need to be further understood.

Ordered arrays of $\mathrm{L}_{0} \mathrm{FePt}$ clusters at a large scale are created by template-mediated self assembly. They have coercivities of 13.4 and $10.2 \mathrm{kOe}$, respectively, when measured perpendicular and parallel to the plane of the dots arrays. The self-organized magnetic arrays find applications in high density magnetic recording, nanodevices, and other related nanotechnology.

Theoretical calculations indicate that magnetization reversal in weakly coupled granular magnets is very similar to Stoner-Wohlfarth coherent rotation. Reduced anisotropy due to surface and interface imperfections yields a disproportionately strong coercivity reduction. With increasing interactions, there is a transition to a discrete pinning regime, where the magnetization remains nearly coherent in any given grain but a kind of a domain wall forms between the grains. Typically, the transition from single-grain rotation to discrete pinning is accompanied by a coercivity maximum. 
For practical applications, it is important to be able to control the magnetic nanostructure properties such as grain size and size distribution, orientation, coercivity, interactions and other properties. However, simultaneous control of these parameters remains a significant challenge.

\section{Acknowlegements}

The authors gratefully acknowledge technical assistance from X.Z. Li for TEM, L.P. Yue for AFM and MFM and Z.G. Sun for cluster deposition. This work was supported by DOE, INSIC, NSF-MRSEC, W.M. Keck Foundation, NRI and CMRA.

\section{References}

1. D.J. Sellmyer, M.L. Yan, Y. Xu and R. Skomski, IEEE Trans. Magn. 41 (2005), p. 560.

2. D.J. Sellmyer, Nature 420 (2002), p. 374.

3. H. Zeng, J. Li, J.P. Liu, Z.L. Wang and S. Sun, Nature 420 (2002), p. 395.

4. R. Wood, IEEE Trans. Magn. 36 (2002), p. 36.

5. N. Honda, K. Ouchi and S. Iwasaki, IEEE Trans. Magn. 38 (2002), p. 1615.

6. M.H. Kryder and R.W. Gustafson, J. Magn. Magn. Mater. 287 (2005), p. 449.

7. D. Weller, A. Moser, L. Folks, M.E. Best, W. Lee, M.F. Toney, M. Schwickert, J.-U. Thiele and M.F. Doerner, IEEE Trans. Magn. 36 (2000), p. 10.

8. Y. Xu, Z.G. Sun, Y. Qiang and D.J. Sellmyer, J. Magn. Magn. Mat. 266 (2003), p. 164

9. Y. Xu, Z.G. Sun, Y. Qiang and D.J. Sellmyer, J. Appl. Phys. 93 (2003), p. 8289.

10. M.L. Yan, N. Powers and D.J. Sellmyer, J. Appl. Phys. 93 (2003), p. 8292.

11. H. Zeng, M.L. Yan, N. Powers and D.J. Sellmyer, Appl. Phys. Lett. 80 (2002), p. 2350.

12. Y.C. Sui, W. Liu, L.P. Yue, X.Z. Li, J. Zhou, R. Skomski and D.J. Sellmyer, J. Appl. Phys. 97 (2005), p. 10J304.

13. J. Zhou, R. Skomski, K.D. Sorge and D.J. Sellmyer, Scrip. Mater. 53 (2005), p. 453.
14. H. Zeng, S. Sun, J. Li, Z.L. Wang and J.P. Liu, Appl. Phys. Lett. 85 (2004), p. 792.

15. Y. Xu, M.L. Yan and D.J. Sellmyer, IEEE Trans. Magn. 40 (2004), p. 2525.

16. Y. Xu, M.L. Yan, J. Zhou and D.J. Sellmyer, J. Appl. Phys. 97 (2005), p. 10J320.

17. Y.F. Xu, M.L. Yan, D.J. Sellmyer, Advanced Magnetic Nanostructures, in: R. Skomski, D.J. Sellmyer (Eds.), Springer, 2006, pp. 295, Ch. 8.

18. M.L. Yan, H. Zeng, N. Powers and D.J. Sellmyer, J. Appl. Phys. 91 (2002), p. 8471.

19. Y. Shao, M.L. Yan and D.J. Sellmyer, J. Appl. Phys. 93 (2003), p. 8152

20. M.L. Yan, X.Z. Li, L. Gao, S.H. Liu, D.J. Sellmyer, R.J.M. van de Veerdonk and K.W. Wierman, Appl. Phys. Lett. 83 (2003), p. 3332.

21. S. Sun, C.B. Murray, D. Weller, L. Folks and A. Moser, Science 287 (2000), p. 1989.

22. Y.C. Sui, D.R. Acosta, J.A. González-León, A. Bermúdez, J. Feuchtwanger, B.Z. Cui, J.O. Flores and J.M. Saniger, J. Phys. Chem. B. 105 (2001), p. 1523.

23. Y.C. Sui, R. Skomski, K.D. Sorge and D.J. Sellmyer, Appl. Phys. Lett. 84 (2004), p. 1525.

24. Y.C. Sui, B.Z. Cui, L. Martinez, R. Perez and D.J. Sellmyer, Thin Solid Films 406 (2002), p. 64.

25. Skomski R, Coey JMD, Permanent Magnetism, IOP, Bristol, 1998

26. R. Skomski, J. Phys.: Condens. Mater. 15 (2003), p. R841.

27. W. Scholz, D. Suess, T. Schrefl and J. Fidler, J. Appl. Phys. 95 (2004), p. 6807.

28. O.N. Mryasov, U. Nowak, K.Y. Guslienko and R.W. Chantrell, Origin of the anomalous temperature dependence of magnetic anisotropy in layered FePt ferromagnets, Europhys. Lett. 69 (2005), p. 805.

29. R. Skomski, A. Kashyap and D.J. Sellmyer, IEEE Trans. Magn. 39 (2003), p. 2917.

30. R. Skomski and J.M.D. Coey, Phys. Rev. B 48 (1993), p. 15812 .

31. J. Zhou, A. Kashyap, Y. Liu, R. Skomski and D.J. Sellmyer, IEEE. Trans. Magn. 40 (2004), p. 2940. 